\title{
The Public Expenditures and Economic Growth: DSGE model for Bosnia and Herzegovina
}

\author{
Nikolina Bošnjak \\ Ph.D candidate at Faculty of Economics, \\ University of Rome "La Sapienza”, Italy \\ Faculty of Economics, \\ University of Banja Luka, Bosnia and Herzegovina
}

\begin{abstract}
The DSGE (Dynamic Stochastic General Equilibrium) methodology attempts to explain the behavior of aggregate economic phenomena, such as economic growth, business cycle, and the effects of monetary and fiscal policy, using macroeconomic models derived from microeconomic foundations. DSGE models study the economy evolution (dynamics) over time. They take into consideration the fact that economy may be affected with random (stochastic) shocks. Still, they include all markets in the economy and assume that those markets balance out rapidly (general equilibrium). DSGE models have become the main tool of macroeconomic analysis, and until now, a huge number of different DSGE models have been developed. They are used for forecasting, different economic policies analysis and giving policy advices. Due to data scarcity and lack of knowledge, indevelopment and many other reasnos, until now there was no application of DSGE models to Bosnia and Herzegovina case. That is why we were motivated to calibrate a small size DSGE model for Bosnia and Herzegovina. In this research we will calibrate a small open economy DSGE model for Bosnia and Herzegovina and use its results to give some advices for economic growth of Bosnia and Herzegovina improvement. The special attention will be given to Public expenditures and TFP influence on Bosnian macroeconomic variables.
\end{abstract}

Keywords: The Public Expenditures and Economic Growth: DSGE model for Bosnia and Herzegovina

\section{Introduction}

Since the J.M. Keynes published "The Means to Prosperity" in 1933 and Great Depression ended, the economists have widely accepted the Keynes theory of public expenditures being the main driving force of economic growth and prosperity during the periods of economic downturn. This Keynes theory was empiricially tested by many researchers and on different samples and in different periods. On the one side, numerous empirical studies find the negative relationship between public spending and economic growth. Barro (Barro, 1991) used the sample of 98 countries in period from 1960 to 1985 and showed the significant negative correlation between economic growth and public expenditures. Ghura (Ghura, 1995) obtained the same result on the sample of 33 African countries. The research based on production function, conducted by Ram (Ram, 1986) disclosed that there is negative influence of public expenditures on economic growth in 115 countries. Lee (Lee, 1995) used different model for his research, the model of endogenous growth of open economy and analyzed 89 developed and undeveloped countries. The results he obtained suggested that public expenditures were correlated with economic growth slow down.

On the other side, many authors showed that there is positive relationship between public expenditures and economic growth. Harko (Harko, 2009) found the existence of positive relationship between public expenditures and per capita GDP in 21 Asian countries. Alexiou (Alexiou, 2007) have discovered the positive correlation between public expenditures-GDP ratio and per capita real GDP level in Greek econoomy. 
All these empirical findings provoked us to analyse the Bosnia and Herzegovina case and to find out is there any connection between Public expenditures and Economic Growth in Bosnia and Herzegovina. This topic was already researched (Bosnjak \& Zlatkovic, 2015), using the Structural Vector Erorr Correction Model. The results were quite interesting and they suggested that the Public Expenditures positive shock will result with short-run decrease of GDP in Bosnia and Herzegovina.

In this research we will go a step further and analyse the same topic, but using different methodology. We will use a small, open economy DSGE model and calibrate it to Bosnia and Herzegovina data in order to observe the impulse response function's results and answer our question.

\section{Small open economy DSGE model}

The DSGE model we developed and calibrated is a small open economy DSGE model that starts from a basic RBC model developed by Kydland and Prscott (Kydland \& Prescott, 1982). This small size model will satisfy the purpose of this research, but we should have in mind that for any further analysis of economic policy of Bosnia and Herzegovina, we should use a DSGE model that would include market frictions as nominal wages and prices rigidity, consumption habit formation, investment adjustment costs, etc.

We will adjust this model to fit small open economy following Gali and Monacelli (Galli \& Monacelli, 2005) small open economy model, modeling international output and inflation rate as exogenous shocks to the economy.

\subsection{Households optimization problem}

In our small open economy model, we assume that representative household that seek to maximize its discounted utility, inhabits the country. Its utility is given with:

$u=E_{t} \sum_{t=0}^{\infty} \beta^{t}\left[\ln C_{t}-\theta N_{t}\right]$

Where household utility is depends on amount of goods consumed in certain period $-C_{t}$ and hours of leisure $-L_{t}$. Leisure, or a free time, are just a fraction of a total available time, and it is perceived as a positive in our utility function. But in order to earn enough money that they can spend on consumption of goods households have to spend one part of their total time in work. This part of time $-\mathrm{N}_{\mathrm{t}}=1-\mathrm{L}_{\mathrm{t}}$ is perceived as negative in their utility function, and represents total hours worked, or employment.

In our utility function there are also parameters - $\theta$, that is elasticity of labor and $\beta$, which is discount factor.

Households earn labor income $W_{t}$ and receive return on stock of their capital invested into firms - RtKt. On the other side they consume $-C_{t}$ amount of goods, which they buy at a certain price level - $P_{t}$ pay real lump-sum taxes $T_{t}$ and invest in firms $-I_{t}$.

Where Permanent Inventory Method of capital accumulation gives investments equation:

$\mathrm{K}_{\mathrm{t}+1}=(1-\delta) \mathrm{K}_{\mathrm{t}}+\mathrm{I}_{\mathrm{t}} \quad \rightarrow \quad \mathrm{I}_{\mathrm{t}}=\mathrm{K}_{\mathrm{t}+1}-(1-\delta) \mathrm{K}_{\mathrm{t}}$

When we consider all this, households are maximizing their discounted utility, subject to their budget constraint:

$W_{t} N_{t}+R_{t} K_{t}=P_{t} C_{t}+T_{t}+K_{t+1}-(1-\delta) K_{t}$

Our Lagrangian function is:

$L=E_{t} \sum_{t=0}^{\infty} \beta^{t}\left[\ln C_{t}-\theta N_{t}+\lambda_{t}\left(W_{t} N_{t}+R_{t} K_{t}-T_{t}-K_{t+1}+(1-\delta) K_{t}-P_{t} C_{t}\right)\right]$

Time separatiion of utility function and focus on only two periods enables us to obtain the first order conditions and to derive the Labor supply equation and standard Euler equation:

$\frac{W_{t}}{P_{t}}=\theta C_{t} \quad$ where $\quad \frac{W_{t}}{P_{t}}$ is real wage level 
$\frac{P_{t+1}}{P_{t}} C_{t}^{-1}=\beta\left[R_{t+1}+(1-\delta)\right] C_{t+1}^{-1}$

\subsection{Technology and Firms optimization}

We assume that production in economy is same for all firms and is given by a standard Cobb-Douglas production function with two production factors - labor and capital. Therefore, production function that we use is given with:

$Y_{t}=A_{t} K_{t}^{\alpha} N_{t}^{1-\alpha}$

Here $A_{t}$ is level of technology used

in economy and a is output elasticity of capital, or capital's share of output, and stands that $0<\alpha<1$. This production function satisfies all standard hypothesis of perfect competition - diminishing returns of production factors and firm's constant returns to scale.

The capital accumulation is given in Equation (2), while we assume that all firms use the same production function and produce differentiated goods but with usage of same technology which is exogenous and follows an stochastic autoregressive process of a first order $A R(1)$, whose log-linearized version is:

$a_{t}=\rho_{a} * a_{t-1}+\epsilon_{a}$

Where, $\rho_{a}<1$ and $\varepsilon a \sim$ iid. $N\left(0, \sigma^{2}\right)$

Firms take price level $\mathrm{P}_{\mathrm{t}}$ and consumption $\mathrm{C}_{\mathrm{t}}$ as given and maximize their profits given production function.

$\max _{N_{t}}\left\{Y_{t}-W_{t} N_{t}-R_{t} K_{t}\right\}$, such that: $Y_{t}=A_{t} K_{t}^{\alpha} N_{t}^{1-\alpha}$

After the formation of Lagrangian expression in respect to production factors - capital and labor, and determination of its First Order Conditions we obtain:

$w_{t}=(1-\alpha) \frac{Y_{t}}{N_{t}} \quad$ and $\quad R_{t}=\alpha \frac{Y_{t}}{K_{t}}$

\subsection{External sector}

Since we derive model for small open economy, the external sector is considered to be exogenous. Law of one price equals the domestic price level with foreign price level. The inflation is defined as a rate of change of price levels, and after loglinearization it is given with:

$\pi_{t}=p_{t+1}-p_{t}$

In our model domestic inflation - $\Pi_{\mathrm{t}}$ is considered to be dependent on a foreign inflation that is exogenous and, thus, modeled according to $A R(1)$ stationary process. After log-linearization, we obtain the following expression for domestic inflation:

$\pi_{t}=\rho_{\pi} * \pi_{t}+\varphi * y_{t}+\epsilon_{p}$

The log-linearized expressions for Export, which depends on external demand for domestic goods, and Import, which represents the domestic demand for consumption of foreign goods, are:

$e_{t}=\varepsilon * \pi_{t}+y_{t}^{*}$ and $m_{t}=\mu * p_{t}+c_{t}$

The wold output is exogeniously detrminated outside the model and represented as AR(1) process:

$y_{t}^{*}=\rho_{y^{*}} * y_{t-1}^{*}+\epsilon_{y^{*}}$

\subsection{Fiscal authorities}


Since monetary authority of Bosnia and Herzegovina - The Central bank of Bosnia and Herzegovina is on currency board regime the absence of active monetary policy is evident. In that case fiscal policy becomes the main economic instrument. In this model tax revenues are proportionate to output, and State through taxes redistributes and consumes one friction of domestic output - $\tau$

$T_{t}=\tau Y_{t}$

For the meter of simplicity, we consider a balanced budget rule in this model, where Government expenditures are equal to taxes, so our budget constraint is:

$$
G_{t}=T_{t}=\tau Y_{t}
$$

In addition, we model government expenditures as exogenous, and their log-linearized expression is:

$g_{t}=\rho_{g} * g_{t-1}+\epsilon_{g}$

\subsection{Market Equilibrium}

Condition for clearing of markets is given in following equation:

$$
Y_{t}=C_{t}+I_{t}+G_{t}+\left(E_{t}-M_{t}\right)
$$

Where part of domestic output is sold on the foreign market and part of domestic consumption is settled with the foreign goods. According to this, we can divide expenditure on an open economy output on four terms: Domestic household consumption, Investment, Government consumption and net trade balance, which is a difference between amount of Export and Import.

\subsection{The model log-linearization}

After the solution of model and log-linearization ${ }^{1}$ of these equations, we obtain following expressions, which make our DSGE model:

$$
\begin{gathered}
y_{t}=a_{t}+\alpha k_{t}+(1-\alpha) n_{t} \\
\vartheta i_{t}=y_{t}-c_{t}(1-\vartheta)+\tau\left(c_{t}-g_{t}\right)+\gamma e_{t}-\mu m_{t} \\
k_{t}=(1-\delta) k_{t-1}+\delta i_{t-1} \\
n_{t}=y_{t}-c_{t}+p_{t} \\
c_{t}=\beta\left(1-\frac{1}{\beta}-\delta\right)\left(y_{t+1}-k_{t+1}\right)-\pi_{t+1}-c_{t} \\
e_{t}=\varepsilon \pi_{t}+y_{t}^{*} \\
m_{t}=\sigma p_{t}+c_{t} \\
\pi_{t}=p_{t+1}-p_{t} \\
\pi_{t}=\rho_{\pi} * \pi_{t-1}+\varphi y_{t}+\epsilon_{p} \\
y_{t}^{*}=\rho_{y^{*}} * y_{t-1}^{*}+\epsilon_{y^{*}}
\end{gathered}
$$

\footnotetext{
${ }^{1}$ For the log-linearization of nonlinear solution of stochastic model we used a two-step method, which is consisted of: 1. Logarithmic approximation of equations in the model and 2. Total differentiation of these equations around the steady state.
} 


$$
\begin{aligned}
& a_{t}=\rho_{a} * a_{t-1}+\epsilon_{a} \\
& g_{t}=\rho_{g} * g_{t-1}+\epsilon_{g}
\end{aligned}
$$

Where parameter $\vartheta$ is given with: $\vartheta=\frac{\alpha \beta}{\frac{1}{\beta}-1+\delta}$ and description of variables is following:

$C_{t}-$ total domestic household consumption

$n_{t}$ - employment level

$p_{t}-$ domestic consumer price level

$\pi_{t}-$ domestic inflation

$y_{t}$ - domestic output

$e_{t}-$ export

$m_{t}-$ import

$g_{t}$ - government consumption

it - investments

$y_{t}^{*}$ - international output

\section{DSGE model calibration of Bosnia and Herzegovina}

After development of the model and its log-linearization we will calibrate the model to correspond to Bosnia and Herzegovina data. First we will shortly describe the economy of Bosnia and Herzegovina and data used in this research.

\subsection{The economy of Bosnia and Herzegovina}

After the signing of Dayton Agreement, in December 1995, which ended a 3,5 year long civil war, Bosnia and Herzegovina obtained its independence but it had to face dual challenge: recovery after the war and transition from socialism to capitalism. Bosnian economy and infrastructure were destroyed during the war, and big resources coming from foreign aid supported intensive growth of GDP in first years after the war. After this initial jump GDP continued to rise with stable and dynamic path of economic growth, with average annual growth rate of approximately $6 \%$ in period from 2000 to 2008 . Nevertheless, because of low starting point of Bosnia and Herzegovina GDP even this growth rate of GDP was insufficient for B\&H to catch up to the economies of EU member nations.

Another, bigger, problem was that this type of dynamic growth was a result of very strong growth of domestic expenditures and investments that were financed by the increase foreign donations, credit lines and foreign remittances.

Since economic growth of B\&H in was not a result of successful implementation of structural, institutional and economic reforms its sustainability was questionable. When the first effects of World Economic Crises reflected on the Bosnian economy in 2008 they caused decrease foreign investments, foreign remittances and exports. Foreign investments grew after 2001 and in average were around 6,5\% of GDP till 2008. In 2009 they had sharply dropped to $0.8 \%$ of GDP and slightly recovered in following years, reaching $2 \%$ of GDP in 2011. Foreign remittances were around $40 \%$ of GDP after war, and in the following years, their share in GDP slowly decreased. This happened probably due to GDP growth, since their nominal level was growing until 2008 when World Crises caused their sharp fall, which continued in following years, until personal remittances share in GDP reached its minimum of $10 \%$ in 2011. All this together with decrease of foreign demand for Bosnia and Herzegovina goods, followed by decrease of exports and sharp jump of trade deficit led to sharp fall of GDP. The movement of Bosnia and Herzegovina per capita GDP, Export and Import can be seen on Figure 1. 
Figure 1 - Per capita GDP, Export and Import of Bosnia and Herzegovina

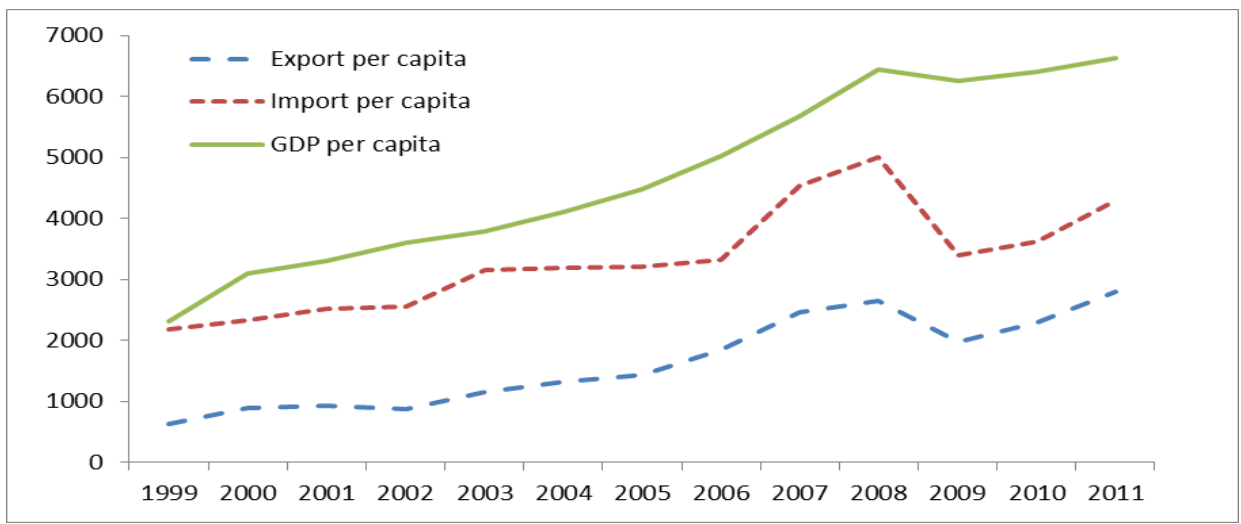

(Source: Central Bank of Bosnia and Herzegovina database)

With external debt to GDP ratio up to $55 \%$ of GDP, and public debt around $40 \%$ Bosnia and Herzegovina is, comparing to other transitional economy countries from its region, still not being overburdened with debt. The problem is that those credits are not used for investment into real economy sector. They are mostly used for financing of domestic final consumption, which decreased slowly from $138 \%$ of GDP in 1999 to $101 \%$ in 2009 and remained constant in following years. This constant problem of overconsumption is mostly caused by final consumption of households, which ranged from 103\% of GDP in 2002 to approximately $80 \%$ in last four years period. Although Bosnia and Herzegovina is constantly spending more than it produces it is almost on the last position in Europe when we observe Final Consumption per capita (only Albania citizens are spending less) (European Commission).

Bosnia and Herzegovina is constantly having negative trade balance that in period from 2000 to 2008 in average was around $43 \%$ of GDP while it dropped to $26 \%$ in 2009 because of slowing down the economic activity caused by Economic Crises. Bosnia and Herzegovina mostly exports base metals and base metal products, machines, devices, mechanical and electric devices, mineral origin products, chemical industry products and furniture.

In structure of import the highest shares are taken by mineral origin products (mostly oil), machines, devices, mechanical and electric devices, food products, chemical industry products and base metals.

The deficit of trade balance is high, it is only partially covered with positive services trade balance and income, and current transfers balance, leaving Bosnia and Herzegovina current account balance with average deficit around $9 \%$ of GDP in last 6 years.

Bosnia and Herzegovina is thought it's all post war history having a structural problem of high unemployment rate, which have decreased slowly from $40 \%$ in 2000 to approximately $24 \%$ in 2008 and 2009 . This high unemployment rates are not only placing pressure on country budget, but they are causing conflicts due to uneven distribution of income between employed and unemployed persons. Higher inequality in income results in high crime rates, higher degree of corruption, higher macroeconomic instability and even lower live expectancy. All this are obstacles to recovery and sustainable growth of Bosnia and Herzegovina economy. 
Now, according 2012 data, Bosnia and Herzegovina, with GDP per capita PPP of 9235 US \$ is the poorest country in Europe, and it is struggling to overcome all political and structural problems that play main obstacles on its way to economic recovery.

\subsection{Public Expenditures in Bosnia and Herzegovina}

In Bosnia and Herzegovina through Public Expenditures State consumes around 45\% of GDP. Comparing the share of public expenditures in Bosnia and Herzegovina with other transitional economy countries, we can easily notice that public expenditures in Bosnia and Herzegovina are at slightly higher level than in other more developed neighbor countries. When we take into consideration a quite modest economic growth of Bosnia and Herzegovina's economy, it opens a question of effectiveness of Bosnian fiscal and economic policy.

When we consider structure of Bosnia and Herzegovina public expenditures we can see that the biggest share of Public Expenditures in Bosnia and Herzegovina goes to Social benefits - around 35,1\%, than around $29,1 \%$ goes to Employee compensations, $24,4 \%$ to Use of goods and services and $4,2 \%$ to Subsidies. All this shares are calculated using data from Table 1 (Central Bank of B\&H).

Table 1 - BH Government Finances, Structure of Consolidated Revenues and Expenditures

\begin{tabular}{|c|c|c|c|c|c|c|c|c|c|c|c|c|}
\hline & 莺 & 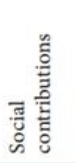 & 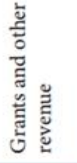 & 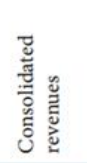 & 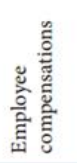 & 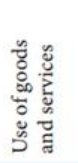 & 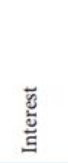 & 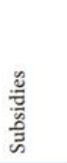 & 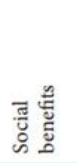 & 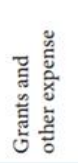 & 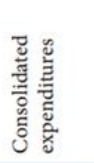 & 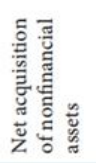 \\
\hline 2003 & $3,223.6$ & $1,877.8$ & 919.6 & $6,021.0$ & $1,783.5$ & $1,518.4$ & 107.2 & 154.8 & $1,749.7$ & 366.7 & $5,680.4$ & 237.9 \\
\hline 2004 & $3,401.8$ & $2,002.8$ & 975.5 & $6,380.2$ & $1,776.2$ & $1,414.8$ & 84.4 & 184.4 & $1,965.4$ & 471.4 & $5,896.7$ & 229.5 \\
\hline 2005 & $4,002.4$ & $2,100.6$ & $1,019.1$ & $7,122.1$ & $1,834.7$ & $1,601.4$ & 96.4 & 217.0 & $2,212.2$ & 397.8 & $6,359.5$ & 351.8 \\
\hline 2006 & $4,947.1$ & $2,536.2$ & $1,103.1$ & $8,586.4$ & $2,222.7$ & $1,986.0$ & 108.0 & 310.4 & $2,426.5$ & 492.4 & $7,546.0$ & 489.6 \\
\hline 2007 & $5,536.5$ & $2,908.9$ & $1,387.3$ & $9,832.7$ & $2,534.7$ & $2,220.9$ & 110.8 & 378.2 & $3,030.6$ & 553.5 & $8,828.8$ & 745.8 \\
\hline 2008 & $5,946.3$ & $3,568.7$ & $1,388.1$ & $10,903.1$ & $3,022.3$ & $2,462.0$ & 123.6 & 439.6 & $3,945.1$ & 607.0 & $10,599.6$ & 842.8 \\
\hline 2009 & $5,351.9$ & $3,638.6$ & $1,352.0$ & $10,342.5$ & $3,155.2$ & $2,489.4$ & 123.9 & 418.5 & $3,951.0$ & 526.5 & $10,664.5$ & 748.0 \\
\hline 2010 & $5,640.2$ & $3,813.0$ & $1,409.4$ & $10,862.6$ & $3,169.8$ & $2,593.1$ & 122.7 & 476.6 & $3,770.3$ & 707.8 & $10,840.3$ & 634.2 \\
\hline 2011 & $6,032.2$ & $4,036.4$ & $1,288.5$ & $11,357.1$ & $3,336.9$ & $2,088.2$ & 161.4 & 402.8 & $4,330.3$ & 589.1 & $10,908.7$ & 771.1 \\
\hline
\end{tabular}

Source: http://www.cbbh.ba

When compared with other transitional countries from its region (Croatia, Serbia, Montenegro, FYR Macedonia, Bulgaria, Romania and Slovenia) with 29,1\% of Public Expenditures being spend on public employee compensations, B\&H is having the highest share of Employee compensations in Public Expenditures. When observing EU 27 average share of $22 \%$ of Employee compensations in Public expenditures we can conclude that Bosnia and Herzegovina is spending far too much on its public sector. Bosnia and Herzegovina is also spending too much on Intermediate consumption. Its share of $24,4 \%$ of Public expenditures are highest in region, and it is double of EU 27 average of around $12 \%$.

Together with this Bosnia and Herzegovina spends the highest share of Public expenditures $-35,1 \%$ on Social benefits. Taken together around $88,6 \%$ of Public expenditures in Bosnia and Herzegovina is used for current spending, and is having no effect on future growth of B\&H economy. All this speaks about inefficiency of B\&H public sector.

\subsection{Data description and model calibration}

Data used in this analysis are taken from Central Bank of Bosnia and Herzegovina yearly reports and World Bank database (World Bank). Originally we had annual data on GDP, Inflation, Employment, Household final consumption, Gross capital formation, Real wage level, Export of goods and services, Import of goods and services and Public expenditures Bosnia and Herzegovina. All data were given for period 1999-2011, in current LCU prices. Using Inflation, we obtained all data 
constant 1998 BAM prices, and dividing them with estimated population of Bosnia and Herzegovina we got per capita values of our observations.

We set a - the capital share of output to be equal to 0.33 , that is consistent with labor share of output of 0.66 or $2 / 3$ of their total available time spend on working.

$\beta$, the discount factor is assumed to be 0.99 , which corresponds to riskless annual return of $4 \%$.

The rate of capital depreciation $-\delta$ is 0.025 , which is standard estimated depreciation rate, used in DSGE models.

We set $\tau$, the fraction of GDP consumed by the state through taxes and public expenditures to be 0.44 in case of Bosnia and Herzegovina, since Government of Bosnia and Herzegovina spends around 44\% of its GDP through Public expenditures.

For calibration of other parameters, we used GMM - Generalized Method of Moments in Eviews 5 software. We aldo had to use HP filter in order to create a monthly data and to increase the number of observations to be able to apply the GMM. For estimation of parameter $\varepsilon$ we used GMM over log per capita exports data and log inflation data. As a proxy for world output we used log per capita EU 27 GDP data.

The calibration with GMM method over log import, log inflation and log Household consumption data gave us the value of $\sigma$ parameter.

For estimation of $\gamma$ and $\mu$ parameters, we used log data on investments, household consumption, government expenditures, GDP, export and import.

The exogenous variables propagation parameters - $\rho y^{*}, \rho g$ and $\rho \pi$ were estimated using EU 27 GDP per capita, public expenditures and inflation rate data, respectively.

In Table 2, we have given values of all estimated parameters used in model calibration for Bosnia and Herzegovina.

Table 2 - Parameters calibration

\begin{tabular}{lll}
\hline$\alpha=0.33$ & $\beta=0.99$ & $\delta=0.025$ \\
\hline $\boldsymbol{T}=0.44$ & $\varepsilon=0.22$ & $\sigma=0.38$ \\
$\gamma=0.42$ & $\mu=0.86$ & $\rho_{y^{*}}=0.99$ \\
$\rho_{g}=0.99$ & $\rho_{\pi}=0.98$ & $\rho_{a}=0.9$ \\
\hline
\end{tabular}

(Source: Author)

\section{Model simulation results}

Using Dynare for Matlab, and parameters calibrated for Bosnia and Herzegovina, as given in Table 2, we obtain the results of stochastic simulation of our DSGE model. Those results under Governemnt expenditure shock are shown on Figure 2, and observing them we can notice some interesting results.

Figure 2 - Simulated IRFs under Government expenditures positive shock 

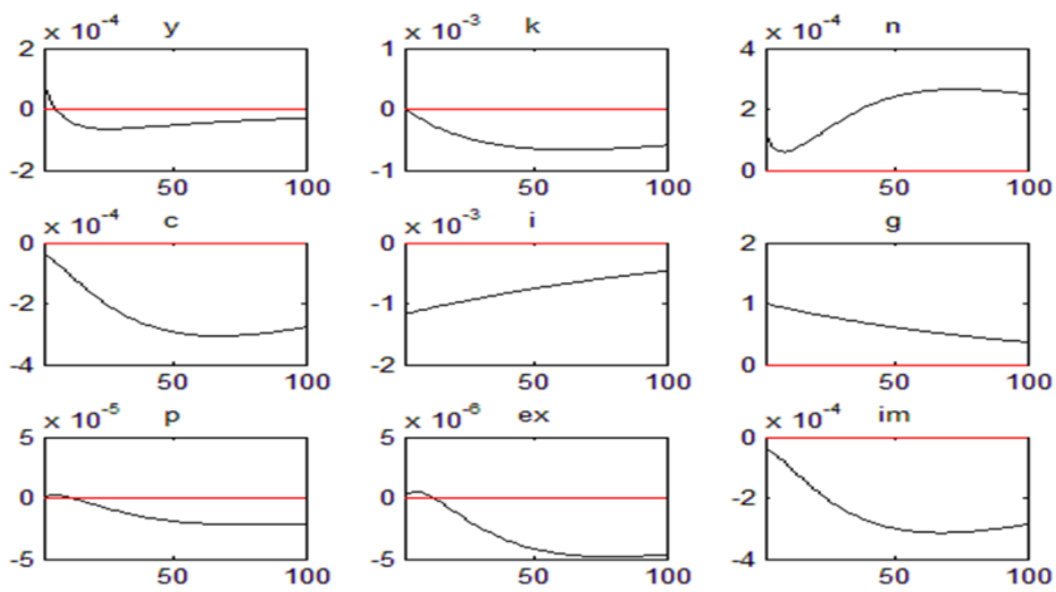

The Impulse Response Functions show us the response of the each variable of the system, when system is threates with unit shock. The interesting result, when we observe IRF's under Public Expenditures shock is that after initial small jump, the GDP of Bosnia and Herzegovina will decrease. Thus, we obtained the same results as in Bosnjak and Zlatkovic (2015). The Growth of Public Expenditures will negatively affect the GDP.

Gross Capital Formation (Investments) IRF shows that Investments have a negative response on a positive Public expenditures shock and in long run it returnes to its steady state. The similar situation is with Consumption, too.

When it comes to employment, we will have a positive response of employment in short-run. Thus, the growth of Public Expenditures will improve the employment and we cn comment that it will create new work places, but without the creation of new output.

Export and Import have the same sign of response on positive Public expenditures shock in both models. They both have negative effects.

The same kind of analysis is done on IRFs under Total Factor Productivity shock. We can observe the Impulse Response Functions of all variables in the DSGE model under TFP shock on Figure 3.

Figure 3 - Simulated IRFs under TFP shock 

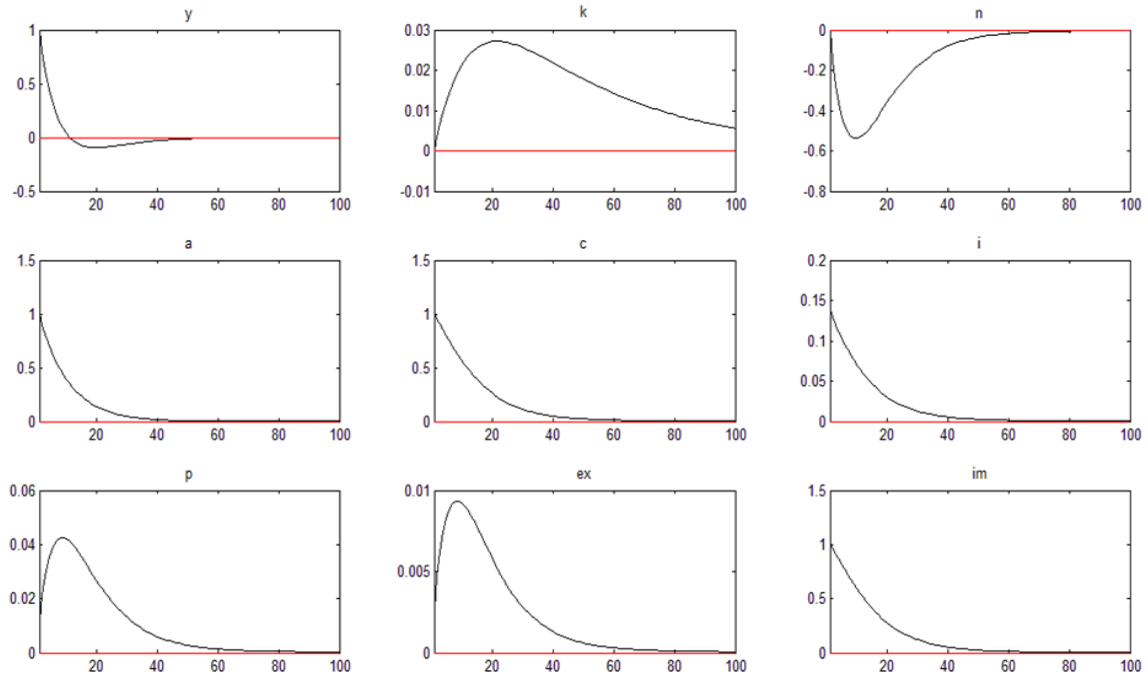

Comparing results of this theoretical model, with previously obtained results from empiricaly based SVAR model (Bosnjak \& Zlatkovic, 2015) we may notice that in general IRFs obtained by DSGE model simulation show reactions of much higher intensity on imapct, while empiricaly generated IRFs reactions are much smoother on shock's impact.

Observing the IRFs of GDP we can conclude that in case of DSGE model simulation GDP jumps instantaniousely under TFP shock and after showing even small negative effects returns to its steady state after 40 periods.

Employment reacts negatively, but after initiall jump returns to its steady state. The Household final consumption will have immediate positive response that will diminish gradually. This return to a steady state can be explained with fact that we have used a simple DSGE model without consumption habit formation, so it is probably not able to catch the real behavior of final consumption effects.

Investments have a positive reaction on TFP shock in both models, and the same is with Import and Export. They both increase, but Import's effects overpass the Exports effects causing the growth of trade balance deficit in long run.

Observing the overall responses of macroeconomic variables under TFP shock, we can conclude that small open economy DSGE model that we calibrated for Bosnia and Herzegovina in general fits well the empirically based SVAR model in Bosnjak and Zlatkovic. The differences that are noticed are caused with the simplicity of the standard DSGE model, which does not contain consumption habit formation, investment adjustment costs, price rigidities and other market frictions. The standard DSGE model specified on this way is satisfying all needs of this analysis, but for some further analysis of possible economic policies effects or predictions of macroeconomic variables movements it would be useful to develop and calibrate the larger DSGE model that would include different market frictions.

\section{Conclusion}

The Government of Bosnia and Herzegovina is redistributing and spending around $45 \%$ of its GDP. This share of Public expenditures in GDP is not large comparing to other countries expenditures. The problem arises when we consider Public expenditures structure, where the largest part of public expenditures are spend on current transfers such us employee compensations, social transfers and goods and services expenditures. This structure of Public expenditures is a decent 
explanation why Bosnia and Herzegovina is still undeveloped although its Public expenditures are at level of more developed countries.

The complex structure of Bosnia and Herzegovina Government, the duality of public institutions and lack of coordination among them are prohibiting conduction of unique and effective economic policy. This inefficiency of Bosnia and Herzegovina public sector and its high level of consumption are considered to be an important obstacle to Bosnia and Herzegovina economic growth. Because of that, they are a subject of big public attention in recent years.

That is why in this research we have focused on the analysis of response of Bosnia and Herzegovina economy on decrease of Public expenditures and TFP shock, which implies that some structural and organizational improvements had occurred.

In this paper, we wanted to verify can standard small size DSGE model well fit the behavior of Bosnia and Herzegovina macroeconomic variables, and does it coincides with SVAR analysis results. The results we obtained state that in general, long run terms DSGE model gave us same results as SVAR model. However, there are differences when we observe the instantaneous reactions. The DSGE model IRFs in short term can be significantly different from SVAR IRFs. The explanation of this can be found in DSGE model specification that does not include some standard New Keynesian assumptions - the prices staggering, nominal wage rigidities, investment adjustment costs, consumption habits formation and others.

Still DSGE model that we have used in this thesis gave us useful results that in combination with SVAR model results enabled us to bring out some conclusions about Bosnia and Herzegovina economy. As we already mentioned we are mostly interested in effects of Public expenditures and TFP shock on other macroeconomic variables.

The Public expenditures negative shock will, according our findings, lead to long run positive effects on GDP. These positive effects will be followed with consumption and investment fluctuations and theirs decrease in short run. Those negative impacts on total output are overpassed by trade balance deficit decrease that is evident from both models results. Therefore, we can conclude that cuts in Public expenditures are highly recommended for Bosnia and Herzegovina economic growth.

The Total Factor Productivity shock will have positive effects on Bosnian GDP, which will diminish after a while and return to its steady state. Nevertheless, the effects on overall economy are not so bright. The growth of output will increase already oversized Final consumption. The additional problem for Bosnia and Herzegovina economy represents the fact that this consumption increase will be mostly done through trade balance deficit growth. Bosnia and Herzegovina is already having problems with high trade balance deficit; therefore, its growth due to TFP shock would only increase Bosnian economy instability.

Based on DSGE model for Bosnia and Herzegovina economy, the overall recommendation for policy makers in Bosnia would be that they should focus on Public expenditures decrease, and growth of public sector efficiency. Only after conduction of public sector reforms the attention should be focused on organization and usage of new technologies in production.

\section{References}

[1] Alexiou, C. (2007). Unraveling the "Mystery" Between Public Expenditure and Growth: Empirical evidence from Greece. International Journal of Economics, Vol.1, No.1, 21-31.

[2] Barro, R. J. (1991). Economic Growth in a Cross-Section of Countries. Quarterly Jouornal of Economics No. 106, 407-443.

[3] Bosnjak, N., \& Zlatkovic, M. (2015). The Influence of Public Expenditures and Total-factor Productivity on the Economic Growth of Bosnia and Herzegovina. In B. Krstic, \& Z. Paszek, The Determinants of Competitiveness (pp. 161-182). Nis: Faculty of Economics, University of Nis.

[4] Central Bank of B\&H. (n.d.). Retrieved from http://www.cbbh.ba/Content/Read/8

[5] Central Bank of Bosnia and Herzegovina database. (n.d.). Retrieved September 1, 2015, from http://statistics.cbbh.ba:4444/Panorama/novaview/SimpleLogin_en.aspx 
[6] European Commission. (n.d.). European statistics. Retrieved from http://ec.europa.eu/eurostat

[7] Galli, J., \& Monacelli, T. (2005). Monetary Policy and Exchange Rate Volatility ina Small Open Economy. Review of Economic Studies.

[8] Ghura, D. (1995). Macro Policies, External Forces and Economic Growth in Sub-Saharan Africa. Economic Development and Cultural Change Vol.43, No.4, 759-778.

[9] Harko, A. N. (2009). Size of Government and and Growth Rate of Per Capita Income in Selected asian Developing Coountries. 28. International Research Journal of Finance and Economics.

[10] Kydland, F. E., \& Prescott, E. (1982). Time to Build and Aggregate Fluctuations. Econometrica.

[11] Lee, J. W. (1995). Capital Goods Imports and Long-run Growth. Journal of Development Economics, Vol. 48, 91-110.

[12] Lozev I., (2010): A small open economy model with financial accelerator for Bulgaria: The role of fiscal policy and the currency board, Bulgarian National Bank

[13] Ram, R. (1986). Government Size and Economic Growth: A New Framework and some Evidence from Cross-Section and Time Series Data. The American Economic Review, Vol.76, No. 1, 191-203.

[14] World Bank. (n.d.). Retrieved from http://data.worldbank.org/ 